Letter

\title{
Polymer photovoltaic devices with highly transparent cathodes
}

\author{
Fang-Chung Chen ${ }^{\mathrm{a}, *}$, Jyh-Lih Wu ${ }^{\mathrm{b}}$, Kuo-Huang Hsieh ${ }^{\mathrm{c}}$, Wen-Chang Chen ${ }^{\mathrm{c}}$, Shih-Wei Lee ${ }^{\mathrm{d}}$ \\ a Department of Photonics and Display Institute, National Chiao Tung University, Hsinchu 300, Taiwan \\ ${ }^{\mathrm{b}}$ Department of Photonics and Institute of Electro-optical Engineering, National Chiao Tung University, Hsinchu 300, Taiwan \\ ${ }^{\mathrm{c}}$ Institute of Polymer Science and Engineering, National Taiwan University, Taipei 106, Taiwan \\ ${ }^{\mathrm{d}}$ Axun Tek Solar Energy Co. Ltd., Luzhu 821, Taiwan
}

\section{A R T I C L E I N F O}

\section{Article history:}

Received 19 June 2008

Received in revised form 31 July 2008

Accepted 6 August 2008

Available online 23 August 2008

\section{PACS: \\ 82.35.Np}

85.30.Tv

Keywords:

Polymer

Photovoltaic

Transparent

Solar cells

\begin{abstract}
A B S T R A C T
In this paper, we demonstrate semi-transparent polymer solar cells employing a transparent cathode configuration, made of cesium carbonate $\left(\mathrm{Cs}_{2} \mathrm{CO}_{3}\right) /$ silver $(\mathrm{Ag}) /$ indium tin oxide (ITO), which exhibited high transmittance in the visible regime. The device performance of the semi-transparent devices was significantly improved after thermal post-annealing and incorporating an Al counter-electrode (CE) grid. Further, the short-circuit current density increased almost linearly with the incident light intensity, suggesting efficient charge collection ability of the transparent cathode. Overall, the semi-transparent polymer solar cell exhibits a remarkable power conversion efficiency of $2.09 \%$.
\end{abstract}

(c) 2008 Elsevier B.V. All rights reserved.
Recently the interest in organic photovoltaic devices (OPVs) has risen steadily owing to their unique properties, such as light weight, low cost, and mechanical flexibility $[1,2]$. The power conversion efficiency (PCE) of OPVs based on the concept of bulk heterojunction has been achieved up to $\sim 5 \%$ [2-4]. To achieve high device performance, efficient absorption of solar radiation is one of the major concerns. However, the use of a thicker active layer to enhance the light absorption is limited by the short diffusion length of excitions and the low mobility of charge carriers $[5,6]$. One possible solution is to fabricate a highly transparent OPV [6-8] and to ultimately stack with the other conventional cell, thereby absorbing more solar radiation by the multiple active layers in the multiple-device structure. The concept of such "stacked" cells has been reported by Shrotriya et al. [6]. Furthermore, OPVs with high transpar-

\footnotetext{
* Corresponding author. Tel.: +886 3 5131484; fax: +886 35735601 .

E-mail address: fcchen@mail.nctu.edu.tw (F.-C. Chen).
}

ency could be also applied onto other interesting applications, such as power-generating windows [8].

An ideal transparent cathode for stacked devices must simultaneously have high efficiency of electron collection and high transparency [6]. For many organic electronics, an ultra-thin interlayer is usually inserted between the organic active layer and the metal cathode to enhance electron injection and to reduce the contact resistance. For example, LiF is commonly used in organic light-emitting diodes $[9,10]$. Additionally, cesium carbonate $\left(\mathrm{Cs}_{2} \mathrm{CO}_{3}\right)$ has been recently reported to be another promising interlayer material [11-15]. In this work, we demonstrated a transparent cathode structure, $\mathrm{Cs}_{2} \mathrm{CO}_{3} /$ silver $(\mathrm{Ag}) /$ indium tin oxide (ITO), for achieving semi-transparent polymer solar cells. In comparison with the LiF/Al configuration, $\mathrm{Cs}_{2} \mathrm{CO}_{3} / \mathrm{Ag}$ possesses several advantages. First, unlike LiF, the function of $\mathrm{Cs}_{2} \mathrm{CO}_{3}$ is relatively insensitive to the choice of the cathode metal [14,15], allowing us to use Ag instead of $\mathrm{Al}$ as the conductor. Further, $\mathrm{Ag}$ is more environmentally 
stable than Al. From the other view point of optical properties, the skin depth of $\mathrm{Ag}(\sim 13 \mathrm{~nm})$ is longer than that of $\mathrm{Al}$ $(\sim 7 \mathrm{~nm})$ in the visible range. As a result, a thicker Ag film can be deposited to reduce the sheet resistance without compromising the light transmittance. In addition, the thicker Ag film can also provide more effective protection of the polymer films from the damage caused by ITO sputtering.

The devices were fabricated on patterned indium tin oxide (ITO)-glass substrates. After cleaning, the ITO glass was dried in an oven and then treated with UV-ozone. By spin coating, the substrates were covered with a thin layer of poly(3,4-ethylenedioxythiophene):poly(styrenesulfonate) (PEDOT:PSS), and were subsequently baked at $120^{\circ} \mathrm{C}$ for $1 \mathrm{~h}$. The active layer, consisting of poly(3-hexyl thiophene) (P3HT) and [6,6]-phenyl- $\mathrm{C}_{61}$-butyric acid methyl ester (PCBM) dissolved in 1,2-dichlorobenzene (DCB) with a weight ratio of $1: 1$, was spin-coated on the top of PEDOT:PSS. The polymer blend was thermally annealed at $110{ }^{\circ} \mathrm{C}$ for $15 \mathrm{~min}$. To complete the device, an ultra-thin interlayer of $\mathrm{Cs}_{2} \mathrm{CO}_{3}(\sim 1 \mathrm{~nm})$ and $\mathrm{Ag}$ were thermally evaporated under a vacuum of $\sim 6 \times 10^{-6}$ torr, sequentially, and finally capped by rf sputtered ITO. The ITO sputtering was conducted at a power of $50 \mathrm{~W}$ under Ar atmosphere $\left(3 \times 10^{-3}\right.$ torr). The optimization of the thicknesses of $\mathrm{Ag}$ and ITO is quite crucial, since there was a trade-off between the sheet resistance and the transmittance of the electrode. After trying various thicknesses of $\mathrm{Ag}$ and ITO, it was found that the optimum thicknesses for Ag and ITO were $7 \mathrm{~nm}$ and $100 \mathrm{~nm}$, respectively. In order to reduce the sheet resistance of the transparent cathode, a 60-nm thick Al counter-electrode (CE) grid was incorporated by thermal evaporation. The areas of the CE grid and the overall device defined through various shadow masks were $0.6 \mathrm{~mm}^{2}(0.12 \mathrm{~mm} \times 5 \mathrm{~mm})$ and $12 \mathrm{~mm}^{2}$ $(2 \mathrm{~mm} \times 6 \mathrm{~mm})$, respectively. The detailed schematic illustration for the device structure is presented in Fig. 1. For some devices, the thermal post-annealing at $140{ }^{\circ} \mathrm{C}$ for 5 min was further performed in the glove box. The current density-voltage $(J-V)$ characteristics of the devices were measured utilizing a Keithley 2400 source-measure unit. The photocurrent was obtained under illumination from
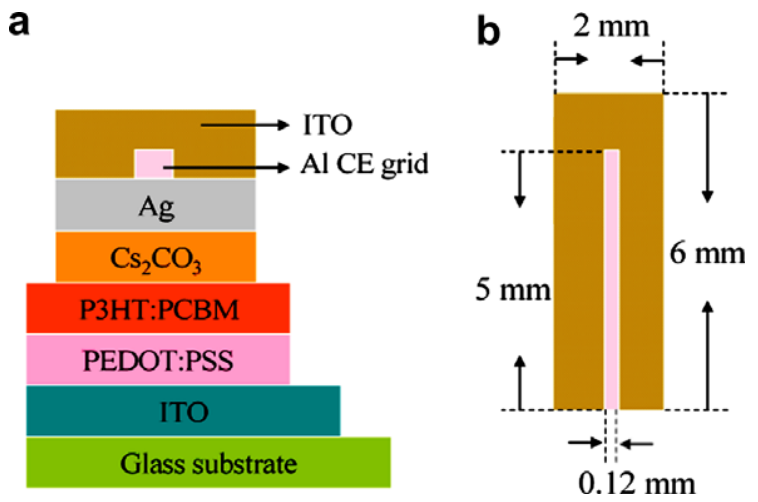

Fig. 1. (a) Device structure of the transparent polymer solar cells incorporating the Al counter-electrode (CE) grid in this study. (b) Detailed schematic illustration for the Al CE grid. a $150 \mathrm{~W}$ Thermal Oriel solar simulator (AM 1.5G). The illumination intensity was calibrated using a standard Si photodiode with a KG-5 filter (Hamamatsu, Inc.) [16]. The transmittance of the transparent cathode was measured using a Perkin Elmer Lamda 950 ultraviolet/visible/near infrared spectrometer.

Fig. 2 shows the $J-V$ characteristics of the polymer solar cells under illumination in this work. The open-circuit voltage $\left(V_{\mathrm{oc}}\right)$, short-circuit current density $\left(J_{\mathrm{sc}}\right)$ and fill factor (FF) of the as-made semi-transparent OPV (Device I) with a structure of ITO/PEDOT:PSS/P3HT:PCBM/C $\mathrm{Cs}_{2} \mathrm{CO}_{3} /$ $\mathrm{Ag}(7 \mathrm{~nm}) / \mathrm{ITO}(100 \mathrm{~nm})$ were $0.45 \mathrm{~V}, 3.72 \mathrm{~mA} / \mathrm{cm}^{2}$, and $23.24 \%$, respectively, resulting in a PCE of $0.39 \%$. The poor performance of the semi-transparent device was probably due to the physical damage of the polymer blends caused by ITO sputtering as well as the relatively high sheet resistance of the cathode (Ag/ITO). Nevertheless, after Device I was post-annealed at $140{ }^{\circ} \mathrm{C}$ for $5 \mathrm{~min}$, the device performance was dramatically improved (Device II in Fig. 2). In fact, post-annealing has been proposed to enhance the device performance of OPVs by several research groups [3,17-19]. Since no obvious variation in absorption was observed after the post-annealing treatment, we also attribute the enhanced PCE to the improvement of the organics/cathode interface as well as the increased charge mobility [3,17-19].

To understand the nature of charge transport in OPVs, the $J_{\mathrm{sc}}$ dependence on the incident light intensity $\left(P_{\text {in }}\right)$ was further studied. Fig. 3a clearly shows that the $J_{\mathrm{sc}}$ followed a power-law dependence, $J_{\mathrm{sc}} \propto\left(P_{\text {in }}\right)^{s}$. After the post-annealing treatment, the exponential factor $(s)$ deduced from the linear fit to the experimental data rose from 0.71 to 0.86 . However, this value is still a little lower than that of the device with $\mathrm{Cs}_{2} \mathrm{CO}_{3} / \mathrm{Ag}(100 \mathrm{~nm})$ cathode ( $s=0.95$, not shown here). This is probably due to the relatively higher sheet resistance of the cathode (Ag/ITO). In

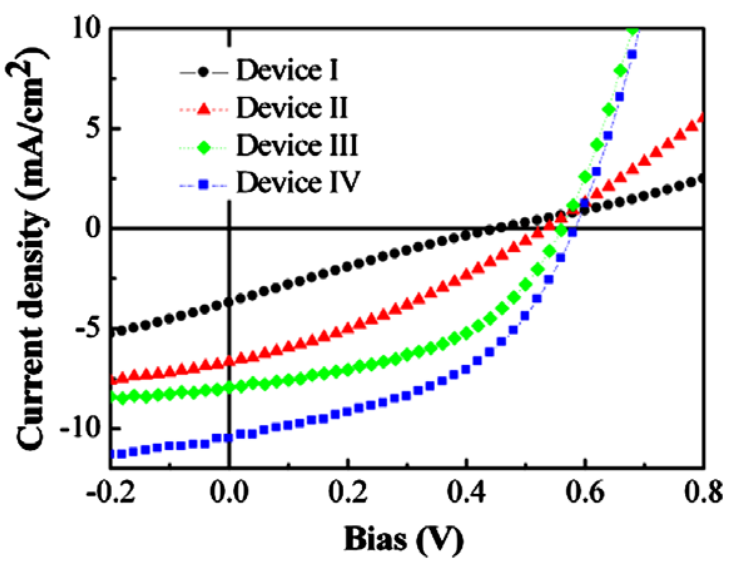

Fig. 2. $J-V$ characteristics of semi-transparent polymer solar cells in this study under $100 \mathrm{~mW} / \mathrm{cm}^{2}$ illumination (AM $1.5 \mathrm{G}$ ). Device I: the as-made device (๑); Device II: Device I with post-annealing treatment ( $\boldsymbol{\Delta})$; Device III: Device II incorporating an Al CE grid ( $)$; Device IV: Device III with an $\mathrm{Ag}$ mirror underneath when illuminating $(\mathbf{\square})$. Note that the photoactive layers for all the devices were thermally annealed at $110^{\circ} \mathrm{C}$ for $15 \mathrm{~min}$ and post-annealing was performed at $140^{\circ} \mathrm{C}$ for $5 \mathrm{~min}$ for Device II, III, and IV. 

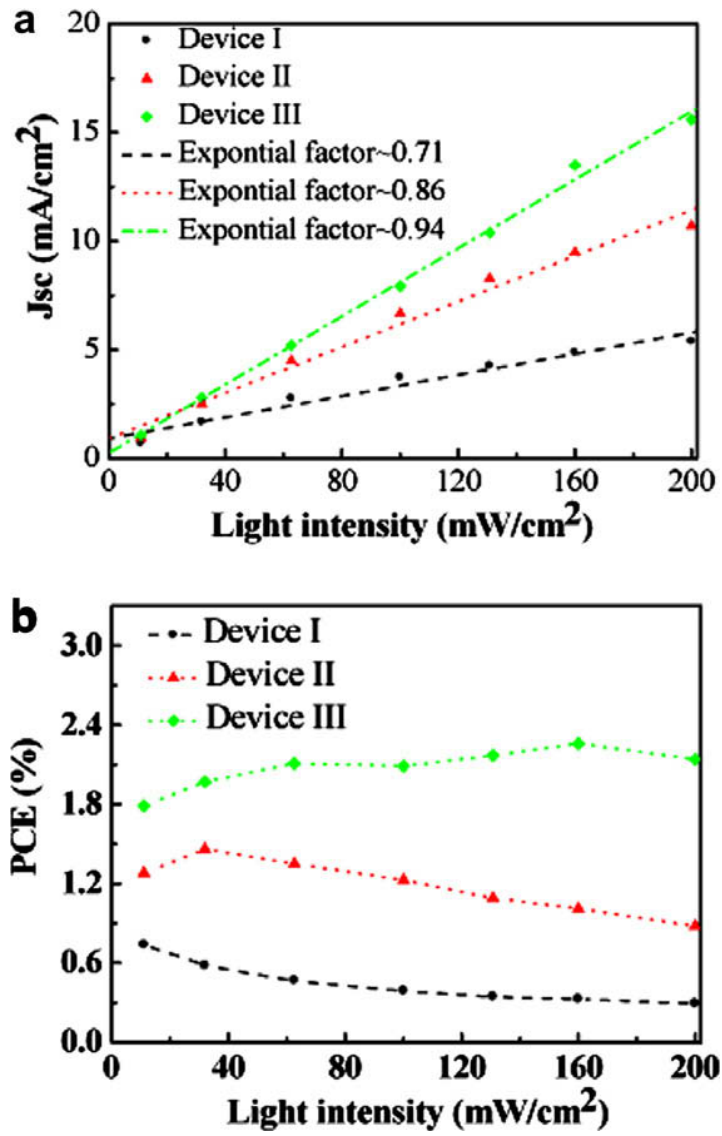

Fig. 3. (a) Short-circuit current density $\left(J_{\mathrm{sc}}\right)$, and (b) power conversion efficiency (PCE) as a function of incident light intensity $\left(P_{\text {in }}\right)$.

order to overcome this problem, an Al counter-electrode (CE) grid with $5 \%$ shadow fraction was utilized to reduce the sheet resistance of the cathode. After incorporating the CE grid (Device III), the FF of the semi-transparent OPV was notably improved, yielding a PCE of $2.09 \%$ (Device III in Fig. 2). Furthermore, the exponential factor was also raised to 0.94 , indicating the absence of space charges in the devices [20,21]. This assumption can be further confirmed from the dependence of the efficiency on the illumination intensity (Fig. 3b). Unlike Device I or Device II, which showed a negative correlation once the intensity was larger than $30 \mathrm{~mW} / \mathrm{cm}^{2}$, Device III exhibited rather stable efficiencies at higher intensities. The incident photo-to-electron conversion efficiency (IPCE) curves for the four devices are also depicted in Fig. 4. Device III, as expected, exhibited higher IPCE than Device I or II. It is worth noticing that the PCE of Device III can be further improved to $2.83 \%$ by placing an $\mathrm{Ag}$ mirror behind the device while illuminating (Device IV). The improved PCE is believed to be attributed to the reduced photo loss through the transparent cathode. This somehow explained why the semitransparent OPVs are typically inferior to conventional devices with thick metals as the cathodes. All the photovoltaic characteristics are summarized in Table 1.

Fig. 5 displays the transmittance spectrum of the $\mathrm{Cs}_{2} \mathrm{CO}_{3} / \mathrm{Ag}(7 \mathrm{~nm}) / \mathrm{ITO}(100 \mathrm{~nm})$ transparent cathode. As

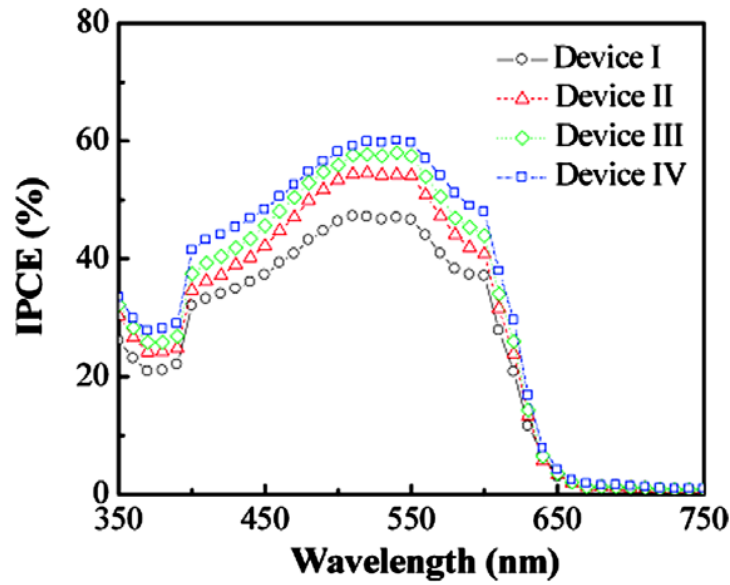

Fig. 4. The incident photo-to-electron conversion efficiency (IPCE) curves.

Table 1

The photovoltaic characteristics of the polymer solar cells in this study

\begin{tabular}{lllll}
\hline & $V_{\text {ос }}(\mathrm{V})$ & $J_{\text {sc }}\left(\mathrm{mA} / \mathrm{cm}^{2}\right)$ & FF $(\%)$ & PCE (\%) \\
\hline Device I & 0.45 & 3.72 & 23.24 & 0.39 \\
Device II & 0.55 & 6.66 & 33.50 & 1.23 \\
Device III & 0.57 & 7.93 & 46.24 & 2.09 \\
Device IV & 0.59 & 10.50 & 45.68 & 2.83 \\
\hline
\end{tabular}

shown in Fig. 5, the transparent cathode exhibited high transmittance $(\sim 70 \%)$ in the visible regime. Further, we noted that the incorporation of a $5 \%$ CE grid did not significantly diminish the transparency. Assuming that the $\mathrm{CE}$ grid is completely opaque, the simulated transmittance spectrum for the transparent cathode with an Al CE grid ( $T_{\text {simu. }}$ ) can be obtained by the following relationship: $T_{\text {simu. }}=T_{\text {mea. }} \times\left(1-\tau_{\mathrm{s}}\right)$, where $\tau_{\mathrm{s}}$ is the area fraction of the $\mathrm{CE}$ grid ( $\tau_{\mathrm{s}}=0.05$ in our case). As a consequence, with the help of the CE grid, the PCE of semi-transparent OPVs can

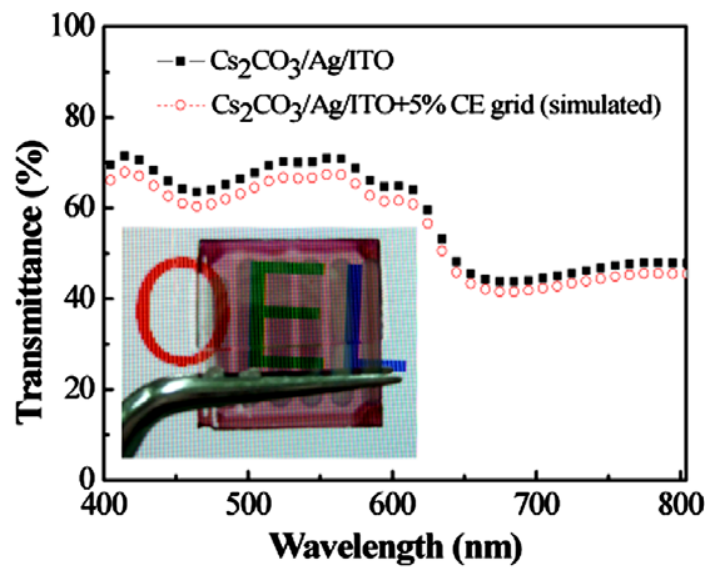

Fig. 5. The transmittance spectrum of the $\mathrm{Cs}_{2} \mathrm{CO}_{3} / \mathrm{Ag}(7 \mathrm{~nm}) / \mathrm{ITO}(100 \mathrm{~nm})$ transparent cathode and the simulated transmittance spectrum of transparent cathode with a $5 \% \mathrm{Al} \mathrm{CE}$ grid. The inset shows the picture of the semi-transparent device. 
be significantly enhanced without dramatically sacrificing the overall transmittance. This is of much importance for some applications, such as stacked cells or tandem cells.

In conclusion, we demonstrated semi-transparent polymer solar cells comprising a $\mathrm{Cs}_{2} \mathrm{CO}_{3} / \mathrm{Ag} / \mathrm{ITO}$ structure as the transparent cathode. We also found that the device performance of the semi-transparent OPVs can be significantly improved through the post-annealing treatment. Further, with the help of the Al CE grid, the semi-transparent OPV exhibited a power conversion efficiency of $2.09 \%$.

\section{Acknowledgements}

The authors would like to thank the financial support from Ministry of Economic Affairs under Contract 96-EC17-A-08-S1-015. F.C.C. would also like to acknowledge the support from National Science Council (NSC-97-ET-7009-004-ET) and Ministry of Education ATU program (97W807).

\section{References}

[1] C.J. Brabec, N.S. Sariciftci, JC. Hummelen, Adv. Funct. Mater. 11 (2001) 15.

[2] G. Li, V. Shrotriya, J.S. Huang, Y. Yao, T. Moriarty, K. Emery, Y. Yang, Nat. Mater. 4 (2005) 864.
[3] W.L. Ma, C.Y. Yang, X. Gong, K. Lee, A.J. Heeger, Adv. Funct. Mater. 15 (2005) 1617.

[4] C.J. Ko, Y.K. Lin, F.C. Chen, C.W. Chu, Appl. Phys. Lett. 90 (2007) 063509.

[5] A. Yakimov, S.R. Forrest, Appl. Phys. Lett. 80 (2002) 1667.

[6] V. Shrotriya, E.H.E. Wu, G. Li, Y. Yao, Y. Yang, Appl. Phys. Lett. 88 (2006) 064104.

[7] T. Oyamada, Y. Sugawara, Y. Terao, H. Sasabe, C. Adachi, Jpn. J. Appl. Phys. 46 (2007) 1734.

[8] R.F. Bailey-Salzman, B.P. Rand, S.R. Forrest, Appl. Phys. Lett. 88 (2006) 233502.

[9] Y.Q. Li, M.K. Fung, Z.Y. Xie, S.T. Lee, L.S. Hung, J.M. Shi, Adv. Mater. 14 (2002) 1317

[10] D. Grozea, A. Turak, X.D. Feng, Z.H. Lu, D. Johnson, R. Wood, Appl. Phys. Lett. 81 (2002) 3173.

[11] C.I. Wu, C.T. Lin, Y.H. Chen, M.H. Chen, Y.J. Lu, C.C. Wu, Appl. Phys. Lett. 88 (2006) 152104.

[12] J. Huang, T. Watanabe, K. Ueno, Y. Yang, Adv. Mater. 19 (2007) 739.

[13] G. Li, C.W. Chu, V. Shrotriya, J. Huang, Y. Yang, Appl. Phys. Lett. 88 (2006) 253503.

[14] J.S. Huang, Z. Xu, Y. Yang, Adv. Funct. Mater. 17 (2007) 1966.

[15] F.C. Chen, J.L. Wu, S.S. Yang, K.H. Hsieh, W.C. Chen, J. Appl. Phys. 103 (2008) 103721.

[16] V. Shrotriya, G. Li, Y. Yao, T. Moriarty, K. Emery, Y. Yang, Adv. Funct. Mater. 16 (2006) 2016

[17] F. Padinger, R.S. Rittberger, N.S. Sariciftci, Adv. Funct. Mater. 13 (2003) 85.

[18] G. Li, V. Shrotriya, Y. Yao, Y. Yang, J. Appl. Phys. 98 (2005) 043704.

[19] Y. Kim, S.A. Choulis, J. Nelson, D.D.C. Bradley, S. Cook, J.R. Durrant, Appl. Phys. Lett. 86 (2005) 063502.

[20] V.D. Mihailetchi, H.X. Xie, B. de Boer, L.J.A. Koster, P.W.M. Blom, Adv. Funct. Mater. 16 (2006) 699

[21] W.J.E. Beek, M.M. Wienk, R.A.J. Janssen, Adv. Mater. 16 (2004) 1009. 